\title{
Endarterectomy for symptomatic internal carotid artery web
}

\author{
Joseph Haynes, BA, ${ }^{1}$ Eytan Raz, MD, PhD, ${ }^{2}$ Omar Tanweer, MD, ${ }^{3}$ Maksim Shapiro, MD, ${ }^{2}$ \\ Rogelio Esparza, MD, ${ }^{3}$ David Zagzag, MD, PhD, ${ }^{4}$ Howard A. Riina, MD, ${ }^{3}$ \\ Christine Henderson, MS, PA-C, ${ }^{3}$ Kaitlyn Lillemoe, MD, ${ }^{5}$ Cen Zhang, MD, ${ }^{5}$ Sara Rostanski, MD, ${ }^{5}$ \\ Shadi Yaghi, MD, ${ }^{5}$ Koto Ishida, MD, ${ }^{5}$ Jose Torres, MD, ${ }^{5}$ Brian Mac Grory, MB BCh BAO, MRCP, ${ }^{6}$ and \\ Erez Nossek, MD ${ }^{3}$
}

${ }^{1}$ School of Medicine and Dentistry, University of Rochester, New York; '2Department of Radiology, Section of Neurointerventional Radiology, ${ }^{3}$ Department of Neurosurgery, ${ }^{4}$ Department of Pathology, Section of Neuropathology, and ${ }^{5}$ Department of Neurology, NYU Langone Health, New York, New York; and ${ }^{6}$ Department of Neurology, The Warren Alpert Medical School of Brown University, Providence, Rhode Island

\begin{abstract}
OBJECTIVE The carotid web (CW) is an underrecognized source of cryptogenic, embolic stroke in patients younger than 55 years of age, with up to $37 \%$ of these patients found to have CW on angiography. Currently, there are little data detailing the best treatment practices to reduce the risk of recurrent stroke in these patients. The authors describe their institutional surgical experience with patients treated via carotid endarterectomy (CEA) for a symptomatic internal carotid artery web.
\end{abstract}

METHODS A retrospective, observational cohort study was performed including all patients presenting to the authors' institution with CW. All patients who were screened underwent either carotid artery stenting (CAS) or CEA after presentation with ischemic stroke from January 2019 to February 2020. From this sample, patients with suggestive radiological features and pathologically confirmed CW who underwent CEA were identified. Patient demographics, medical histories, radiological images, surgical results, and clinical outcomes were collected and described using descriptive statistics.

RESULTS A total of 45 patients with symptomatic carotid lesions were treated at the authors' institution during the time period. Twenty patients underwent CAS, 1 of them for a CW. Twenty-five patients were treated via CEA, and of these, 6 presented with ischemic strokes ipsilateral to CWs, including 3 patients who presented with recurrent strokes. The mean patient age was $55 \pm 12.6$ years and 5 of 6 were women. CT angiography or digital subtraction angiography demonstrated the presence of CWs ipsilateral to the stroke in all patients. All patients underwent resection of CWs using CEA. There were no permanent procedural complications and no patients had stroke recurrence following intervention at the latest follow-up (mean $6.1 \pm 4$ months). One patient developed mild tongue deviation most likely related to retraction, with complete recovery at follow-up.

CONCLUSIONS CEA is a safe and feasible treatment for symptomatic carotid webs and should be considered a viable alternative to CAS in this patient population.

https://thejns.org/doi/abs/10.3171/2020.5.JNS201107

KEYWORDS carotid web; ischemic stroke; carotid endarterectomy; cryptogenic stroke; embolic stroke of undetermined source; vascular disorders

$\Lambda$ CAROTID web (CW) is a shelf-like lesion located in the proximal posterior portion of the carotid bulb, considered an atypical form of fibromuscular dysplasia (FMD). ${ }^{1,2}$ This lesion was first described in $1968 ;{ }^{3}$ the "web" term was later coined in 1973 by Momose and New., This physical defect alters laminar flow and functions as a nidus for thromboemboli that can lead to ischemic strokes. ${ }^{5}$ Notably, the amount of stenosis attributed to the presence of a web is not a significant predictor of stroke risk. ${ }^{6,7} \mathrm{CWs}$ may be easily missed on routine diagnostic workup for ischemic stroke as they only rarely cause hemodynamically significant stenosis and can

ABBREVIATIONS ACT = activated clotting time; $\mathrm{CAS}=$ carotid artery stenting; $\mathrm{CEA}=$ carotid endarterectomy; $\mathrm{CTA}=\mathrm{CT}$ angiography; $\mathrm{CW}=\mathrm{carotid}$ web; $\mathrm{DSA}=$ digital subtraction angiography; FMD = fibromuscular dysplasia; SMA = smooth muscle actin.

SUBMITTED April 6, 2020. ACCEPTED May 18, 2020.

INCLUDE WHEN CITING Published online August 28, 2020; DOI: 10.3171/2020.5.JNS201107. 
closely mimic the radiographic appearance of other common lesions at the carotid bifurcation, including arterial dissection, noncalcified atherosclerosis, and intraluminal thrombus. ${ }^{8}$ Evidence suggests that they may have a high risk of early recurrent stroke. ${ }^{9}$

$\mathrm{CW}$ is an underrecognized underlying etiology of cryptogenic strokes in young patients without atherosclerotic risk factors, particularly in women and people of African American or Afro-Caribbean descent. ${ }^{8-15}$ However, there is currently no established treatment protocol. ${ }^{16}$ Medical management alone in patients with symptomatic $\mathrm{CW}$ has been shown to have high stroke recurrence rates, particularly in the first week following the index event.9,13 Joux et al. reported a $30 \%$ recurrence (at a mean follow-up of 25.3 months) of ischemic stroke in medically managed symptoms as opposed to no recurrence in surgically managed patients. ${ }^{13}$ Similarly, Haussen et al. suggested that antiplatelet therapy alone may be insufficient after finding a $29 \%$ recurrence of ischemic events in patients managed medically. ${ }^{9}$ On the other hand, several cases managed surgically have shown no stroke recurrence in patients on follow-up (Table 1). ${ }^{2,5,10,12-14,17,18}$ Carotid artery stenting (CAS) has also been previously reported as an effective treatment modality in CW cases., ${ }^{9,17,19-24}$ While the results are promising, the data are limited and there is no dedicated series of carotid endarterectomy (CEA) for treatment of CW.

\section{Methods}

We performed a retrospective, observational cohort study. We reviewed the medical charts of patients who presented to NYU Langone Health with symptomatic carotid lesions from January 2019 to February 2020. We identified patients who suffered strokes associated with ipsilateral CWs on digital subtraction angiography (DSA) or CT angiography (CTA) and subsequently underwent CEA with pathological confirmation of CW. All CEA procedures were performed under general anesthesia and continuous somatosensory evoked potential monitoring. Patient demographics, past medical history including cardiovascular disease risk factors, radiological images, surgical and pathological results, and clinical outcome were reviewed.

\section{Radiographic Diagnosis of CW}

A CW was defined as an intraluminal, shelf-like projection at the bifurcation or proximal internal carotid artery best seen on sagittal or oblique sagittal imaging (Figs. 1-4). Other etiologies of thromboembolic phenomena such as atheromatous plaque (by virtue of the presence of calcification, lesional irregularity, and/or a pattern of atherosclerosis elsewhere in the extracranial vasculature), arterial dissection (by examining for the presence of a true and false lumen), and intraluminal thrombus (by looking for irregularity and carefully inspecting the geometry of the lesion) were excluded. All diagnoses were adjudicated with a neuroradiologist and a neurosurgeon (who were also co-authors).

\section{Clinical Management and Surgical Approach}

All patients were examined and evaluated by a stroke neurologist, either during the acute stroke event or during their subacute phase in the outpatient clinic. Medical history, baseline neurological examination, and modified Rankin Scale score were documented. Complex cases were presented at our multidisciplinary conference (stroke neurology, neuroradiology, neurointerventional radiology, and vascular neurosurgery). Because the degree of stenosis in CW patients does not predict stroke risk,, 67 it did not significantly impact our management decisions and we opted for CEA of the lesions.

Preoperative assessment of the contralateral carotid artery as well as the circle of Willis was performed according to either formal angiography or CTA, in order to assess risk of carotid trapping during CEA as well as the level of the bifurcation and other anatomical factors that could affect the surgical approach.

All patients were maintained on $81 \mathrm{mg}$ of aspirin upon their stroke presentation. Aspirin was continued before and during their operation and continued in the post-procedure period. All surgeries were performed under general anesthesia by our neuroanesthesia team. Patients were placed supine with the head slightly turned and placed in a donut foam cushion to expose the side of the neck ipsilateral to the lesion. An ultrasound was used to mark the level of the common carotid artery bifurcation. A baseline activated clotting time (ACT) examination was evaluated. A transverse incision along a cervical crease was performed. Cervical dissection and exposure of the carotid bifurcation was performed in a standard fashion. After exposure of the carotid artery bifurcation, vessel loops were placed around the identified vessels including the external carotid artery, superior thyroid artery, internal carotid artery, and common carotid artery. Two thousand units of intravenous heparin was administered, and ACT was assessed 20 minutes after heparin administration. The internal carotid artery was then clamped, followed by the common carotid artery and then the superior thyroid and external carotid artery.

\section{Surgical Approach}

Using a no. 11 blade, an arteriotomy is performed in the common carotid artery inferior to the level of the web and extended using Potts scissors up to the distal level of the $\mathrm{CW}$ in the proximal internal carotid artery. We do not attack the web directly; rather, we perform an endarterectomy "routine" dissection in the media of the vessel wall deeper to the web tissue. We begin the dissection in an area of natural separation in the media between the vessel wall and the CW. Using a surgical Penfield no. 3 dissector and Debakey forceps, a plane between the media and the web tissue is then developed under the operative microscope. We first dissect inferiorly toward the common carotid artery where the tissue is separated off the vessel wall, followed by dissection off the internal carotid artery, and finally off the external carotid artery. The whole CW is included in the circumferential dissection off the carotid artery bifurcation (Video 1, Fig. 5).

VIDEO 1. Clip showing CEA for CW, illustrating complete circumferential endarterectomy for resection of an internal carotid artery web (case 3). Copyright Erez Nossek. Published with permission. Click here to view. 
TABLE 1. Summary of cited series of CWs

\begin{tabular}{|c|c|c|c|c|c|}
\hline Authors \& Year & $\begin{array}{c}\text { No. of Pts } \\
\text { w/ CW } \\
(\% \mathrm{~F})\end{array}$ & $\begin{array}{c}\% \text { African } \\
\text { American or } \\
\text { Afro-Caribbean }\end{array}$ & Tx Modality & $\begin{array}{l}\text { Stroke or TIA Recurrence } \\
\text { After Tx at Latest FU }\end{array}$ & Periprocedural Complication \\
\hline Joux et al., $2014^{13}$ & $25(64)$ & 100 & $\begin{array}{l}\text { CEA }(n=7) \text {, conservative mgmt } \\
(n=18)\end{array}$ & $\begin{array}{l}\text { CEA }(0 \%) \text {, conservative } \\
\text { mgmt }(30 \%)\end{array}$ & None \\
\hline Choi et al., $2015^{5}$ & $7(71.4)$ & 0 & $\begin{array}{l}\text { CEA }(n=4) \text {, conservative mgmt } \\
(n=3)\end{array}$ & $\begin{array}{l}\text { CEA (0\%), conservative } \\
\text { mgmt }(57.1 \%)\end{array}$ & None \\
\hline Coutinho et al., $2017^{11}$ & $5(80)$ & Not reported & Conservative mgmt $(n=5)$ & Not reported & NA \\
\hline Haussen et al., $2017^{9}$ & $24(61)$ & 75 & $\begin{array}{l}\text { CAS ( } n=16) \text {, conservative mgmt } \\
\quad(n=8)\end{array}$ & $\begin{array}{l}\text { CAS }(0 \%) \text {, conservative } \\
\text { mgmt }(29 \%)\end{array}$ & None \\
\hline Compagne et al., 201815* & $12(92)$ & Not reported & NA & NA & NA \\
\hline Brinjikji et al., $2018^{23}$ & $4(75)$ & Not reported & CAS $(n=4)$ & CAS $(0 \%)$ & $\begin{array}{l}\text { Poststent bradycardia in } \\
3 \text { pts }\end{array}$ \\
\hline Sajedi et al., $2019^{14}$ & $14(64)$ & 86 & $\begin{array}{l}\text { CEA }(n=3) \text {, conservative mgmt } \\
(n=11)\end{array}$ & $\begin{array}{l}\text { CEA }(0 \%) \text {, conservative } \\
\text { mgmt NA }\end{array}$ & None \\
\hline Haussen et al., $2018^{24}$ & $24(58)$ & 71 & CAS $(n=24)$ & CAS $(0 \%)$ & $\begin{array}{l}\text { Asymptomatic hypotension/ } \\
\text { bradycardia in } 2 \text { cases }\end{array}$ \\
\hline Pereira et al., $2018^{22}$ & $18(44.4)$ & Not reported & $\begin{array}{l}\text { CEA }(n=2), \text { CAS }(n=6) \text {, conser- } \\
\quad \text { vative mgmt }(n=10)\end{array}$ & $\begin{array}{l}\text { CEA }(0 \%) \text {, CAS }(0 \%) \text {, con- } \\
\text { servative mgmt }(0 \%)\end{array}$ & None \\
\hline Wojcik et al., $2018^{6}$ & $5(100)$ & Not reported & $\begin{array}{l}\text { CEA }(n=1), \text { CAS }(n=2) \text {, conser- } \\
\quad \text { vative mgmt }(n=2)\end{array}$ & $\begin{array}{l}\text { CEA }(0 \%) \text {, CAS }(0 \%) \text {, con- } \\
\text { servative mgmt }(0 \%)\end{array}$ & None \\
\hline Kim et al., $2019^{8} \dagger$ & $9(33)$ & 89 & NA & NA & NA \\
\hline
\end{tabular}

$\mathrm{FU}=$ follow-up; $\mathrm{mgmt}=$ management; $\mathrm{NA}=$ not applicable; pts = patients; $\mathrm{TIA}=$ transient ischemic attack; Tx = treatment.

* Study of CW prevalence.

† Study of CW frequency.

Copious heparinized saline irrigation is then performed. Careful inspection of the vessel wall is performed, and residual free tissue is removed using micro ring forceps. The arteriotomy is closed primarily with a running 6-0 Prolene suture. Prior to final arteriotomy closure, back bleeding is performed from all vessels. Complete closure is then performed. Vessels are released in the following order: the external carotid artery followed by the common carotid artery. We revascularize the common carotid artery into the external carotid artery for 1 minute to clear the bifurcation of any clot, air, or free residuals. We then release the internal carotid artery and achieve complete and final revascularization of the carotid bifurcation. A Doppler probe is utilized to verify flow in all vessels. Continuous somatosensory evoked potential monitoring is used throughout the procedure (see Video 1 of CEA for CW [case 3]).

\section{Pathology}

All formalin-fixed, paraffin-embedded human tissue specimens were obtained from surgical operations. Briefly, formalin-fixed, paraffin-embedded tissue was prepared using conventional histological methods. Serial sections (6
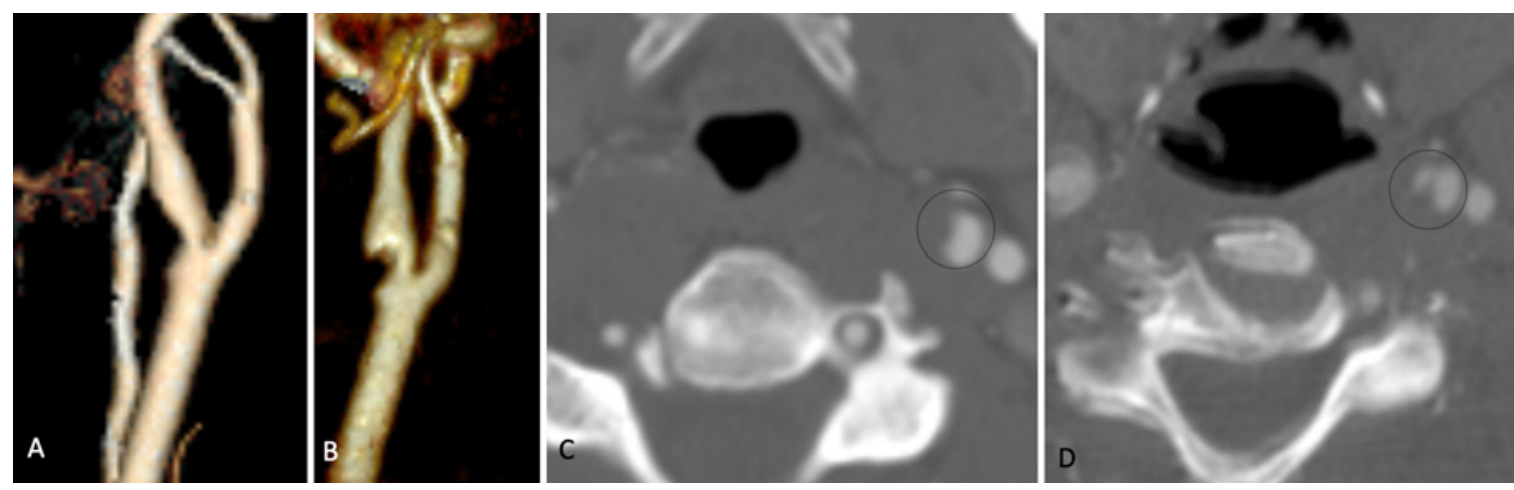

FIG. 1. CTA of a patient (case 2) with recurrent strokes. Reconstruction and axial images upon presentation with ischemic stroke $(\mathbf{A}$ and $\mathbf{C})$; reconstruction and axial images 2 weeks after initial presentation with recurrent strokes (B and D). Note the differences in lesions are most probably due to clot formation over the web (circles). Figure is available in color online only. 


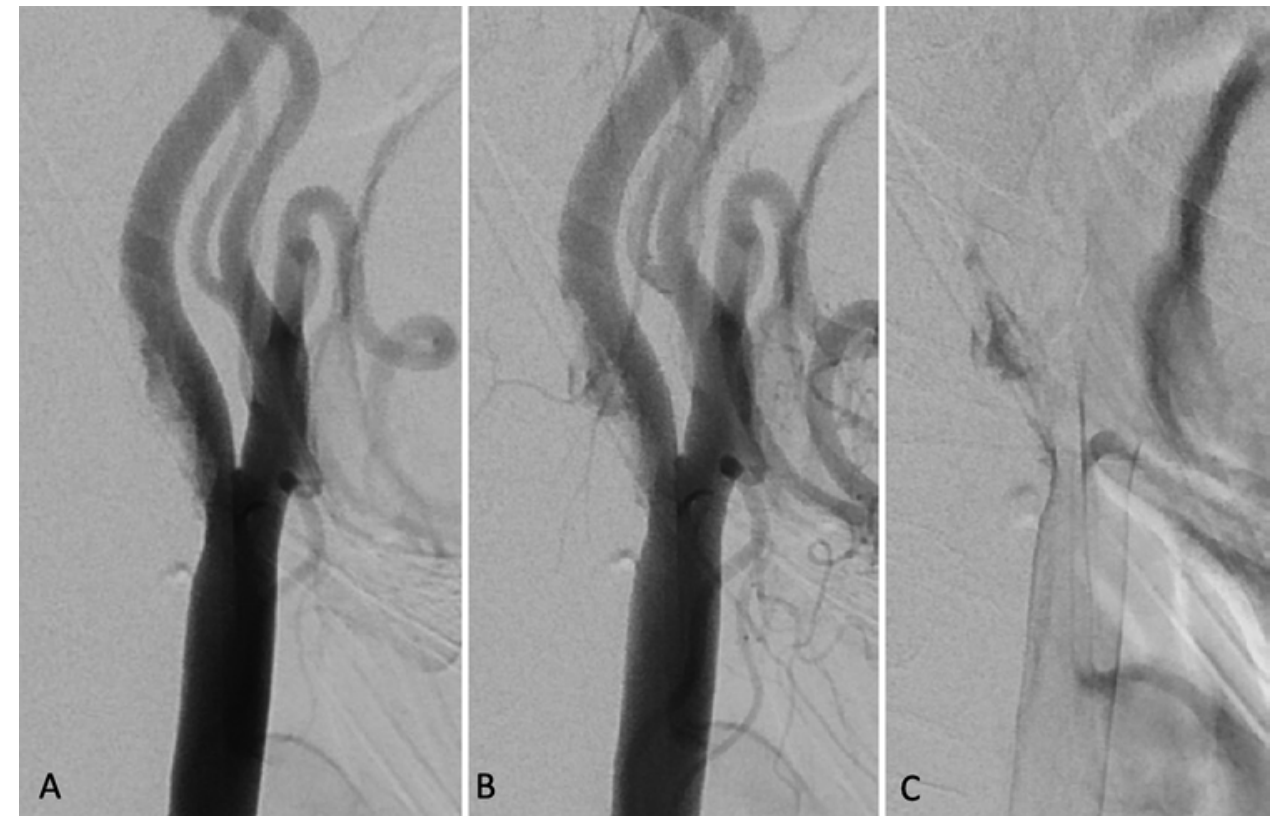

FIG. 2. Case 3. DSA demonstrating lateral projection in the early arterial $(\mathbf{A})$, late arterial $(\mathbf{B})$, and venous $(\mathbf{C})$ phases of a large $\mathrm{CW}$ with significant contrast stagnation at the level of the web.

$\mu \mathrm{M})$ were cut from each paraffin block. One section was stained with $\mathrm{H} \& \mathrm{E}$ for histological assessment.

\section{Results}

\section{Patient Characteristics}

Forty-five patients with symptomatic carotid lesions were identified in our retrospective review. In these patients, 38 lesions $(84.4 \%)$ represented internal carotid artery plaques and $7(15.6 \%)$ were $\mathrm{CWs}$. Of the $\mathrm{CW}$ patients, 6 underwent CEA and 1 had carotid stent placement. All 6 patients who underwent CEA were started on antiplatelet therapy (aspirin) on admission. One patient presented with intracranial large-vessel occlusion and underwent thrombectomy followed by CEA for CW in the subacute phase after stroke presentation. The age range of the cohort was 43-79 years (mean $55 \pm 12.6$ years) and 5 of 6 were women (Table 2). Four patients were African American (66.7\%), one was Hispanic (16.7\%), and one was White (16.7\%). Five $(83.3 \%)$ of the 6 patients had no significant cardiovascular disease risk factors. One patient (case 5; Table 2) had a past medical history of hypertension, hyperlipidemia, and prior tobacco use. The degree of carotid artery stenosis was mild in all patients ( $<50 \%$ carotid occlusion). All patients underwent CEA for resection of CWs as described in the Methods section. All lesions were clearly observed upon performance of arteriotomy and intraluminal inspection. Complete circumferential endarterectomy was performed in all cases for complete resection of the web (Video 1, Figs. 4 and 5). Primary closure of the arteriotomy was performed without a need for an arterial patch in all cases. Neuromonitoring achieved good baseline in all cases, and all were stable during the clamping phase and throughout the procedure. No intraoperative complications were observed. One patient developed mild postoperative tongue deviation with complete recovery at follow-up. There were
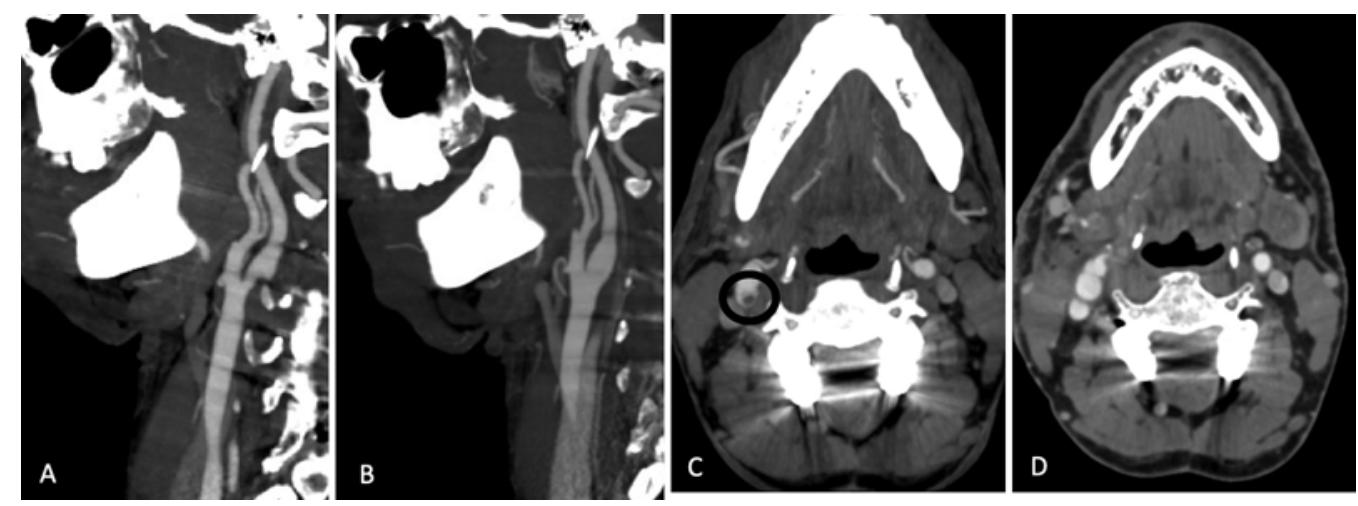

FIG. 3. Case 3. CTA in sagittal and axial views demonstrates a preoperative ( $A$ and $C$ ) and postoperative (B and D) right-sided CW (circle) 

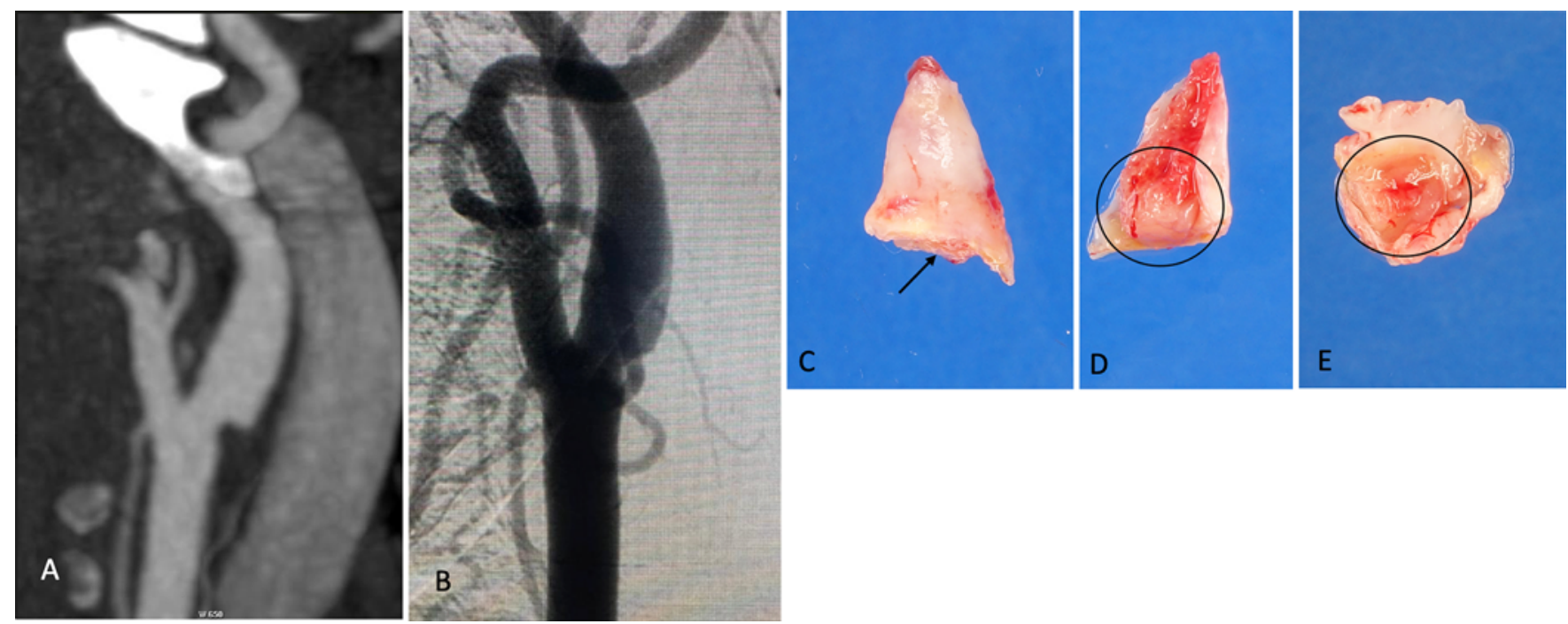

FIG. 4. CTA (A) and formal DSA (B) of a patient (case 5) with recurrent strokes and a CW (C). Macroscopic images showing the extraluminal side (C), luminal side (D), and axial slice (E) of the resected CW (arrow and circles). Figure is available in color online only.

no permanent procedural complications and no patients had stroke recurrence or ischemic events at the latest follow-up (mean $6.1 \pm 4$ months; Table 3).

\section{Pathology}

Pathology sections showed variable degrees of intimal fibrous hyperplasia with medial myxoid and fibrous thickening highlighted by trichrome, azocarmine, or elastic stains. In some cases, fragments of thrombus with variable organization and hemosiderin-laden macrophages were present. In addition, immunostains for smooth muscle actin (SMA) highlighted the spindle cells (Fig. 6). We performed immunostains for CD163-highlighted histiocytic cells. In some cases, neovascularization was marked by immunostains for CD34 or ERG that also highlighted en- dothelial cells. MIB-1 immunostains that recognize the Ki-67 nuclear proliferation-associated antigen revealed a variable but mostly low labeling index.

Classic and pathological features of an atherosclerotic plaque, including structure and composition, were not observed. Common features of an atherosclerotic plaque, including plaque ulceration or rupture, and macrophages or xanthoma cell infiltration were absent. Instead, the pathological examination showed wall thickening with proliferation of fibroblasts but without atherosclerotic change, including classic cholesterol clefts, intraplaque hemorrhages, and lympho-monocytic cell infiltrates that were not detected. Together, all these features allowed a diagnosis of a CW and distinction from a classic atherosclerotic plaque.

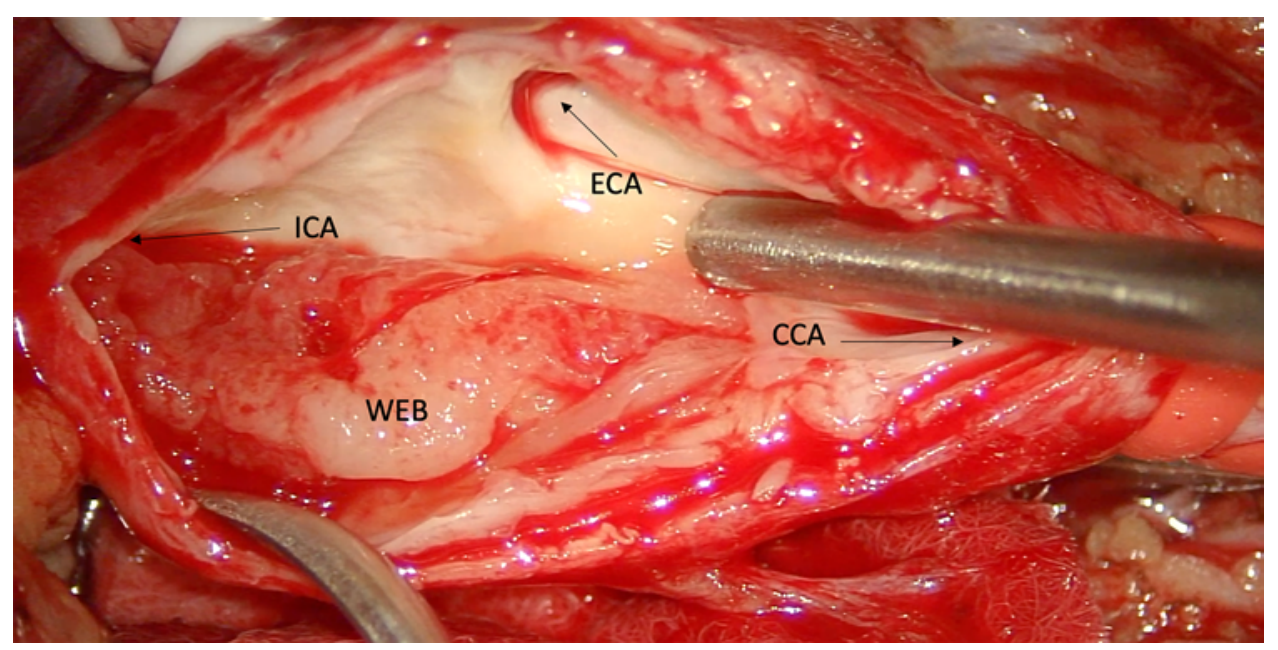

FIG. 5. Case 3. Intraoperative image after right carotid arteriotomy and opening of the vessel at the level of a large CW. CCA = common carotid artery; ECA = external carotid artery; ICA = internal carotid artery. Figure is available in color online only. 
TABLE 2. Patient demographics and clinical characteristics

\begin{tabular}{|c|c|c|c|c|c|c|c|}
\hline $\begin{array}{l}\text { Case } \\
\text { No. }\end{array}$ & $\begin{array}{l}\text { Age } \\
\text { (yrs), } \\
\text { Sex }\end{array}$ & Ethnicity & $\begin{array}{c}\text { Recurrent } \\
\text { Strokes at } \\
\text { Presentation }\end{array}$ & $\begin{array}{l}\text { Previous } \\
\text { Endovascular } \\
\text { Thrombectomy }\end{array}$ & Symptoms & $\begin{array}{l}\text { Atherosclerotic Risk } \\
\text { Factors* }^{*}\end{array}$ & $\begin{array}{c}\text { Other Significant } \\
\text { Past Medical History }\end{array}$ \\
\hline 1 & $49, \mathrm{~F}$ & Hispanic & No & No & $\begin{array}{l}\text { Headache, paresthesia, dressing } \\
\text { apraxia }\end{array}$ & None & \\
\hline 2 & $57, \mathrm{~F}$ & African American & Yes & No & Aphasia, rt-sided weakness & None & \\
\hline 3 & $53, \mathrm{M}$ & African American & Yes & No & Lt hemiparesis & None & $\begin{array}{l}\text { Essential thrombocy- } \\
\text { tosis }\end{array}$ \\
\hline 4 & $79, \mathrm{~F}$ & White & No & No & Rt-sided weakness & None & FMD \\
\hline 5 & $50, \mathrm{~F}$ & African American & No & Yes & $\begin{array}{l}\text { Rt-sided weakness, facial droop, } \\
\text { aphasia }\end{array}$ & $\begin{array}{l}\text { Hypertension, hyperlipi- } \\
\text { demia, former } \\
\text { smoker }\end{array}$ & \\
\hline 6 & $43, F$ & African American & Yes & No & $\begin{array}{l}\text { Dysphasia, rt-sided weakness, } \\
\text { facial droop }\end{array}$ & None & \\
\hline
\end{tabular}

* Atherosclerotic risk factors collected include dyslipidemia, diabetes, hypertension, and smoking history.

\section{Discussion}

CWs are a unique entity, characteristically different from the typical atherosclerotic disease or FMD-associated causes of thromboembolic phenomena. It has been described as an intimal variant of FMD characterized by intimal fibroelastic hyperplasia., ${ }^{1,2}$ Despite a lack of significant stenosis associated with CWs, it is postulated that the physical presence of the $\mathrm{CW}$ causes alterations in laminar flow that facilitates the formation of thromboemboli and increases the risk of ipsilateral recurrent strokes. ${ }^{5}$ Here we describe our recent series of surgical treatment with CEA for symptomatic patients with CW. CEA is safe and effective as a management strategy for CW patients in our series and was associated with $0 \%$ permanent morbidity, mortality, and stroke recurrence during the short-term follow-up period. While CW is not commonly diagnosed, it should be suspected in young, nonwhite, female patients who lack traditional vascular risk factors and present with unihemispheric, cryptogenic stroke. Early diagnosis and effective treatment are key to prevent recurrence of ischemic events in these patients.

Coutinho et al. in a case-control study describe 4 webs in 53 symptomatic carotid cases. They found that all the strokes were ipsilateral to the web and reported an overall prevalence of 9.4\%. ${ }^{11}$ However, others have found a significantly higher prevalence of webs in their patients with undetermined stroke etiology. Sajedi et al. report a prevalence of $21.2 \%$ among patients $18-55$ years old with cryptogenic stroke, with most of their patients being African American and women. ${ }^{10}$ Again, all webs were ipsilateral to the stroke (although 3 patients had bilateral webs). Joux et al. studied an Afro-Caribbean population with a mean age of $46.7 \pm 7.1$ years and found that the presence of CWs was 24 times higher in cryptogenic stroke patients than controls. ${ }^{12}$ They found a $37 \%$ prevalence of webs in these patients and also an overall $23 \%$ prevalence of webs in all young patients with carotid ischemic strokes. Of note, 5 of these patients underwent resection of the web. Haussen et al. reported a case series of CWs where CAS was the primary treatment modality. Sixteen patients $(66 \%)$ underwent successful CAS and had no stroke recurrence at follow-up. ${ }^{9}$ They found that $29 \%$ of patients with cryptogenic strokes had CW. Furthermore, 29\% also had a thrombus superimposed on said CW.

It has been reported that CWs are usually not associated with high-grade vascular stenosis. ${ }^{6,7}$ In our series, all patients had carotid artery stenosis classified as mild $(<$ $50 \%$ carotid occlusion). We have opted to perform CEA as opposed to CAS for symptomatic CW because CEA corrects the wall defect yet does not require the patient to be placed on long-term dual antiplatelet therapy and thus obviates concerns about bleeding risk. This is especially appealing given that the population affected tends

TABLE 3. Patient demographics and surgical characteristics

\begin{tabular}{cccccc}
\hline $\begin{array}{c}\text { Case } \\
\text { No. }\end{array}$ & $\begin{array}{c}\text { Age }(\mathrm{yrs}), \\
\text { Sex }\end{array}$ & Ethnicity & Side of CW & Postop Complications & $\begin{array}{c}\text { Mos From Surgery to } \\
\text { Last Clinical FU }\end{array}$ \\
\hline 1 & $49, \mathrm{~F}$ & Hispanic & $\mathrm{Rt}$ & None & 8.12 \\
\hline 2 & $57, \mathrm{~F}$ & African American & $\mathrm{Lt}$ & None & 0.89 \\
\hline 3 & $53, \mathrm{M}$ & African American & $\mathrm{Rt}$ & None & 8.35 \\
\hline 4 & $79, \mathrm{~F}$ & White & $\mathrm{Lt}$ & None & 6.71 \\
\hline 5 & $50, \mathrm{~F}$ & African American & $\mathrm{Lt}$ & Lt tongue deviation, resolved at FU & 10.9 \\
\hline 6 & $43, \mathrm{~F}$ & African American & $\mathrm{Lt}$ & None & 1.41 \\
\hline
\end{tabular}

None of the patients experienced operative complications or postoperative strokes. 


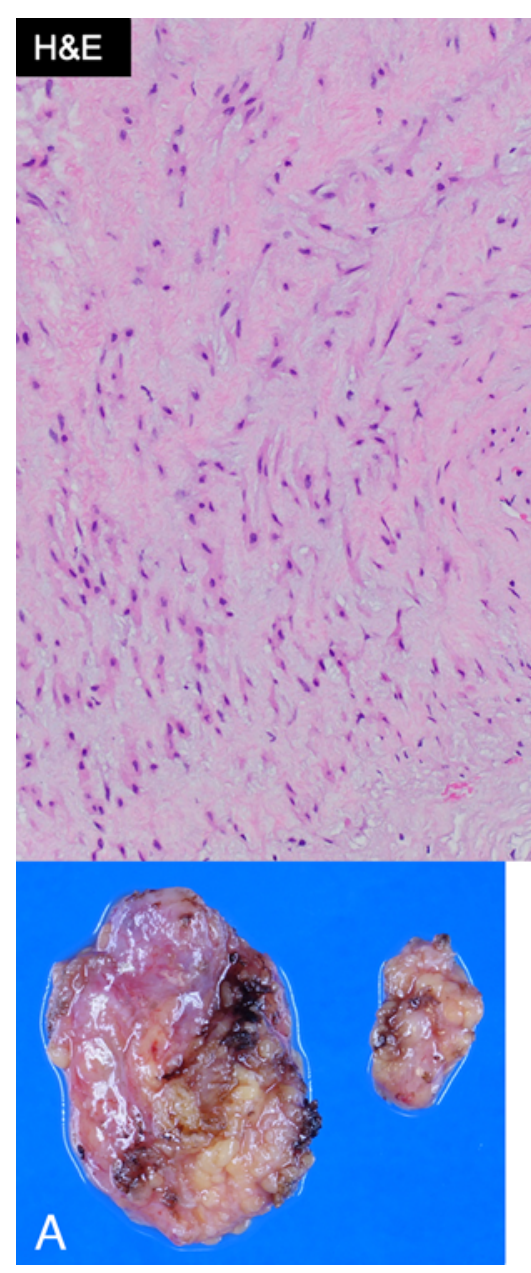

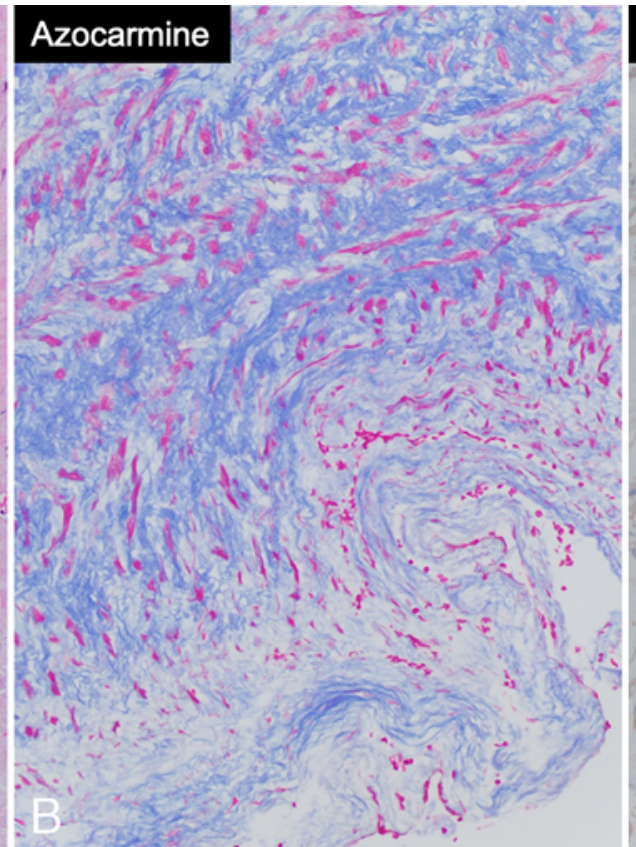

Smooth muscle actin

FIG. 6. Case 3. A: Serial section (lower) with $\mathrm{H}$ \& E stain (upper) shows the spindle cells as well as the myxoid background. B: The azocarmine stain highlights the matrix deposition within the lesion. C: Immunohistochemistry for SMA was performed on a serial section. The spindle cells are immunoreactive for SMA. Original magnification $\times 100$. Figure is available in color online only.

to be younger and lacks traditional vascular risk factors. Moreover, younger patients usually lack complex surgical anatomy related to prior neck surgeries or neck radiation, which would increase the complexity of the surgical approach. Additionally, there is often no contralateral disease that may increase risk during carotid trapping, especially when verifying a patent circle of Willis preoperatively. Thus, we prefer CEA for most symptomatic web patients. During the time period of this study at our institution there was a $15.6 \%$ prevalence (7/45 cases) of CWs among symptomatic carotid lesions. In this report, 6 of 7 patients were treated via CEA and none had any permanent procedural deficits or symptom recurrence.

Technically, according to our experience, the surgical approach for a CW is similar to that of common atherosclerotic carotid artery plaque. Accordingly, we do not recommend trying to solely attack and resect the intraluminal component observed upon arteriotomy and opening of the vessel. This might cause an uneven focal defect in the lining of the vessel wall that may risk an additional thromboembolic event. Thus, we begin with identification of the web tissue and the media at the level of the arteriotomy, followed by dissection and development of a plane deep to the web tissue, with circumferential endarterectomy and complete resection of the web tissue off the level of the bifurcation from the common, internal, and external ca- rotid arteries. Finally, because usually there is no significant narrowing or stenosis at the level of the bifurcation in these cases, we advocate primary closure of the arteriotomy rather than the use of patch graft.

This study is limited by its retrospective nature with the possibility of selection bias, small cohort size, and short follow-up. The diverse patient population and the fact that all interventions were performed in a single institution are also limitations. Conversely, the pathological confirmation of the diagnosis of CW for all cases is a strength. To our knowledge, this represents the largest published case series of endarterectomy as treatment for $\mathrm{CW}$.

\section{Conclusions}

This report adds to the growing body of literature that examines treatment options for patients with CW. CEA appears to be a safe and effective treatment for symptomatic CWs that should be considered as a viable option in this patient population.

\section{References}

1. Osborn AG, Anderson RE. Angiographic spectrum of cervical and intracranial fibromuscular dysplasia. Stroke. 1977; 8(5):617-626.

2. Wirth FP, Miller WA, Russell AP. Atypical fibromuscular 
hyperplasia. Report of two cases. J Neurosurg. 1981;54(5): 685-689.

3. Rainer WG, Cramer GG, Newby JP, Clarke JP. Fibromuscular hyperplasia of the carotid artery causing positional cerebral ischemia. Ann Surg. 1968;167(3):444-446.

4. Momose KJ, New PF. Non-atheromatous stenosis and occlusion of the internal carotid artery and its main branches. Am J Roentgenol Radium Ther Nucl Med. 1973;118(3):550-566.

5. Choi PM, Singh D, Trivedi A, et al. Carotid webs and recurrent ischemic strokes in the era of CT angiography. AJNR Am J Neuroradiol. 2015;36(11):2134-2139.

6. Wojcik K, Milburn J, Vidal G, Steven A. Carotid webs: radiographic appearance and significance. Ochsner J. 2018;18(2): $115-120$

7. Zhang AJ, Dhruv P, Choi P, et al. A systematic literature review of patients with carotid web and acute ischemic stroke. Stroke. 2018;49(12):2872-2876.

8. Kim SJ, Allen JW, Bouslama M, et al. Carotid webs in cryptogenic ischemic strokes: a matched case-control study. $J$ Stroke Cerebrovasc Dis. 2019;28(12):104402.

9. Haussen DC, Grossberg JA, Bouslama M, et al. Carotid web (intimal fibromuscular dysplasia) has high stroke recurrence risk and is amenable to stenting. Stroke. 2017;48(11):31343137.

10. Sajedi PI, Gonzalez JN, Cronin CA, et al. Carotid bulb webs as a cause of "cryptogenic" ischemic stroke. AJNR Am J Neuroradiol. 2017;38(7):1399-1404.

11. Coutinho JM, Derkatch S, Potvin AR, et al. Carotid artery web and ischemic stroke: a case-control study. Neurology. 2017;88(1):65-69.

12. Joux J, Boulanger M, Jeannin S, et al. Association between carotid bulb diaphragm and ischemic stroke in young AfroCaribbean patients: a population-based case-control study. Stroke. 2016;47(10):2641-2644.

13. Joux J, Chausson N, Jeannin S, et al. Carotid-bulb atypical fibromuscular dysplasia in young Afro-Caribbean patients with stroke. Stroke. 2014;45(12):3711-3713.

14. Sajedi P, Chelala L, Nunez-Gonalez J, et al. Carotid webs and ischemic stroke: experiences in a comprehensive stroke center. J Neuroradiol. 2019;46(2):136-140.

15. Compagne KCJ, van Es ACGM, Berkhemer OA, et al. Prevalence of carotid web in patients with acute intracranial stroke due to intracranial large vessel occlusion. Radiology. 2018; 286(3):1000-1007.

16. Wojcik K, Milburn J, Vidal G, et al. Survey of current management practices for carotid webs. Ochsner J. 2019;19(4): 296-302.

17. Phair J, Trestman EB, Yean C, Lipsitz EC. Endarterectomy for a symptomatic carotid web. Vascular. 2017;25(5):553-556.
18. Ozaki D, Endo T, Suzuki H, et al. Carotid web leads to new thrombus formation: computational fluid dynamic analysis coupled with histological evidence. Acta Neurochir (Wien). Published online March 10, 2020. doi:10.1007/s00701-02004272-2

19. Gouveia EE, Mathkour M, Bennett G, Valle-Giler EP. Carotid web stenting. Ochsner J. 2019;19(1):63-66.

20. Martinez-Perez R, Lownie SP, Pandey SK, Boulton MR. Stent placement for carotid web. World Neurosurg. 2017;98: 879.e9-879.e11.

21. Elmokadem AH, Ansari SA, Sangha R, et al. Neurointerventional management of carotid webs associated with recurrent and acute cerebral ischemic syndromes. Interv Neuroradiol. 2016;22(4):432-437.

22. Pereira BJA, Batista UC, Tosello RT, et al. Web vessels: literature review and neurointerventional management. World Neurosurg. 2018;110:e907-e916.

23. Brinjikji W, Agid R, Pereira VM. Carotid stenting for treatment of symptomatic carotid webs: a single-center case series. Intervent Neurol. 2018;7(5):233-240.

24. Haussen DC, Grossberg JA, Koch S, et al. Multicenter experience with stenting for symptomatic carotid web. Intervent Neurol. 2018;7(6):413-418.

\section{Disclosures}

Dr. Riina reports ownership in eVasc Neuro, MedTel, MediVis, ELum, and NTI; being a consultant to Medtronic; and being on the speaker's bureau for Stryker.

\section{Author Contributions}

Conception and design: Nossek, Raz. Acquisition of data: Nossek, Zagzag. Analysis and interpretation of data: Nossek, Haynes, Zagzag. Drafting the article: Haynes. Critically revising the article: all authors. Reviewed submitted version of manuscript: all authors. Approved the final version of the manuscript on behalf of all authors: Nossek. Statistical analysis: Haynes. Administrative/ technical/material support: Shapiro. Study supervision: Nossek.

\section{Supplemental Information \\ Videos \\ Video 1. https://vimeo.com/423557936.}

\section{Correspondence}

Erez Nossek: NYU Langone Health, New York, NY. erez. nossek@nyulangone.org. 